\title{
IMAGEM DIALÉTICA DA INFÂNCIA E ROMPIMENTO DO CONTINUUM HISTÓRICO
}

\author{
Paulo Victor de Albuquerque Silva
}

\begin{abstract}
RESUMO
O projeto metodológico benjaminiano: educar o olhar para as imagens dialéticas que reluzem em meio aos acontecimentos históricos. Decidimos direcionar esse olhar ao mundo minúsculo e feérico da infância. Pretende-se com essas imagens da infância provocar uma ruptura no continuum da história, sustentada pelo ideal de "progresso" ou "época de decadência", duas faces da mesma moeda. A infância através do seu ato de brincar produz imagens que saltam no agora da cognoscibilidade como iluminações profanas e incoerentes. Sem planejamentos ou normatizações, tudo emana de seu corpo como exceção que salta no tempo do agora (Jetztzeit) messiânico.
\end{abstract}

Palavras-chave: Imagem dialética. Criança. Despertar. Continuum Histórico. Exceção.

\section{CHILDHOOD'S DIALECTICAL IMAGE AND BREAKING OF HISTORICAL CONTINUUM}

\begin{abstract}
The benjaminian methodological project: to educate the glance for the dialectical images that shine in the midst of historical events. We decided to address that glance to the minuscule and the faerie world of the childhood. These images of childhood are intended to provoke a rupture in the continuum of history, sustained by the ideal of "progress" or "epoch of decadence," two sides of the same coin. The childhood through its act of play produces images that leap into the now of cognoscibility as profanes and incoherents illuminations. Without planning or standardization, everything emanates from your body as an exception jumping into the Messianic now-time (Jetztzeit).
\end{abstract}

Key-words: Dialectical image. Child. Awakening. Historical continuum. Exception. 


\section{INTRODUÇÃO}

O despertar como um gradual que se impõe na vida tanto do indivíduo quanto das gerações. $O$ sono é seu estágio primário. A experiência da juventude de uma geração tem muito em comum com a experiência do sonho. Sua configuração histórica é configuração onírica. Cada época tem um lado voltado para os sonhos, o lado infantil.

Walter Benjamin, Passagens, 2009, p. 433.

Os indicadores de uma crítica à modernidade nos escritos benjaminianos podem ser encontrados em várias de suas obras. Desde sua juventude, Benjamin lança indícios do sintoma histórico que culminará em sua grande ideia de progresso desenvolvido no fim de sua vida. ${ }^{1} \mathrm{O}$ avanço tecnológico no sistema capitalista de produção, a noção do desenvolvimento científico que visa o controle racional inevitável da natureza, o advento da social-democracia alemã e seu ideal de uma raça pura e superior, questões tão amplamente criticadas pela Escola de Frankfurt, levaram Walter Benjamin a questionar essa força avassaladora do progresso que se propagava arrastando tudo entre as margens dos acontecimentos históricos. Tal percepção acerca de uma marcha idealizada historicamente já é evidente em vários de seus textos, entre os quais podemos encontrar de maneira embrionária o despertar da obra "Rua de mão única" (Einbahnstrasse), onde Benjamin desvela o fenômeno da fragmentação social contemporânea que pode ser manifesta em imagens, locomotivas sociais que agora são reutilizadas dialeticamente. Por meio do estanque imagético do movimento ininterrupto, pretende-se causar uma irrupção dialética material através das próprias imagens provocando um desvio ou um retorno, a contrapelo. ${ }^{2}$

Inspirado pelo desenvolvimento de um novo aparato técnico de grande relevância em sua época, a máquina fotográfica, Benjamin procura captar as imagens do mundo fenomênico das metrópoles modernas através das lentes

\footnotetext{
${ }^{1}$ Nas palavras do próprio autor: "A ideia de um progresso da humanidade na história é inseparável da ideia de sua marcha no interior de um tempo vazio e homogêneo. A crítica da ideia do progresso tem como pressuposto a crítica da ideia dessa marcha." (BENJAMIN, 1985, p. 229).

${ }^{2}$ Fazemos aqui referência à ideia de uma "história a contrapelo" levantada do texto "Sobre o conceito da história".

Mestre em Filosofia (UECE), Graduando em Pedagogia (UFC), Professor efetivo do Município de Fortaleza. Brasileiro, residente em Fortaleza - CE, E-mail: paulovictordealbuquerquesilva@gmail.com
} 
inumanas, com o intuito de deixar as próprias imagens falarem por si. Seu método está no foco, na percepção do olhar, melhor dizendo, no seu direcionar. Passa então a capturar literariamente a imagem dos acontecimentos corriqueiros pertencentes a Einbahnstrasse. Por isso escreve ainda na primeira página de seu livro: "A atuação literária significativa só pode instituir-se em rigorosa alternância de agir e escrever" (BENJAMIN, 1987, 11). A ação seria o direcionamento do olhar para onde o flash paralisador aponta. Agora tudo aquilo que indica uma possibilidade de desvio e que se encontra dentro desta mesma rua que contém uma única indicação passa a ser fotografado por Walter Benjamin. O resultado é um álbum de fotografias contendo somente imagens que captam objetos desviantes, não catalogados, em momentos tão precisos e oportunos que escapam a qualquer pré indicação. Sonhos, lugares, objetos, pessoas, tudo aquilo que chama sua atenção desviando o olhar da placa que aponta o caminho em frente é modelo para o flash. Já que todas as imagens presentes nesta obra manifestam-se como possibilidades de contrassenso e resistência aos espaços pré-fabricados pelo mundo capitalista moderno, que detém como pano de fundo o ideal de progresso da humanidade, propomos o manejo político do desvio projetado pela imagem da infância como iluminação profana material que abre a exceção no agora messiânico através de sua invocação despretensiosa do agir, rompendo com o continuum histórico. Tal objetivo nos leva a afirmar o poder presente na própria infância, algo que somente pôde ser percebido por meio do método dialético da imobilidade elaborado por Benjamin.

A teoria filosófica benjaminiana está menos preocupada com o caráter de engajamento político, que visa uma ação política ininterrupta em busca de seu ideal, como pretendem os marxistas, e mais com a intervenção salvadora no agora preciso. Em um mundo majoritariamente estetizante, pois constituído incisivamente por imagens, Benjamin tinha que alcançar quais elementos, em meio ao dado, faziam reluzir as falhas estruturais deste universo manipulado. Dentre essas instâncias revolucionárias ele depara-se com a criança.

Podemos levantar vários fatores como responsáveis pela descoberta do fenômeno infantil por Walter Benjamin. Em sua vida privada o contato direto com as crianças aconteceu: primeiro com o nascimento de seu filho Stefan em 1917; seu trabalho radiofônico de agosto de 1929 até o seu fim ocasionado pelos nacionalMestre em Filosofia (UECE), Graduando em Pedagogia (UFC), Professor efetivo do Município de Fortaleza.

Brasileiro, residente em Fortaleza - CE, E-mail: paulovictordealbuquerquesilva@gmail.com 
socialistas em 1933, ofício em grande parte direcionado aos jovens alemães recheados com conselhos sobre a vida prática; a pessoa de Asja Lacis que lhe apresentou seu projeto voltado para um teatro infantil na União Soviética; sua visita ao "Museu distrital brandenburguês" para encontrar os velhos brinquedos de Berlim, fato que the despertou o interesse pela produção manufatureira desses objetos. No campo intelectual Benjamin pôde se deparar com os recentes estudos, já que o fenômeno infantil não foi uma questão investigativa por um longo tempo, de vários autores de sua época recente: entre eles a questão da moralidade iluminista em Kant; a problemática envolvendo a faculdade mimética e o jogo infantil em Simmel e principalmente Huizinga; a obra detalhada sobre a história dos brinquedos de Karl Gröber; a teoria do Psicólogo Karl Groos sobre os jogos humanos ou os experimentos pedagógicos de Pestalozzi. Todas essas influências que aproximaram Walter Benjamin às crianças fizeram com que o filósofo enxergasse nelas o seu caráter revolucionário e desviante, salvador ${ }^{3}$.

Ao entrarmos em contato com o mundo feérico da criança percebemos que elas se relacionam com o real através do seu ato de brincar. Uma comunicação direta e sem interrupções entre a criança e o mundo circundante: assim é o modo intrínseco pertencente aos seres vivos que procuram adentrar na existência efetiva. É somente através da brincadeira que a criança sai do "estado natural", aqui entendido como um momento "pré-reflexivo", para penetrar na superestrutura histórica vigente. Essa ligação direta ocorre através da faculdade mimética ${ }^{4}$, pois,

\footnotetext{
3 A percepção de Benjamin sobre o caráter de uma salvação futura da infância também é compartilhada por Bernd Witte quando este explana sobre a presença da criança na obra "Rua de mão única". Para Witte, Benjamin expõe o fenômeno da infância em seu livro pois vislumbra nos pequeninos uma instância viva para a salvação futura da natureza e da humanidade. "No centro do livro, com 30 dos 60 textos, está a criança que o autor foi, sob o título 'ampliações'. Sua figura, capturada em seis instâncias, contém em nível individual a promessa de felicidade que o historiador acreditava poder ler a partir da antiga ligação com o cosmos, no texto final. Ao leitor se apresenta a criança que, no prazer sensível de mordiscar doces, já tem o antegosto da satisfação sexual, a criança que, na felicidade de ler e como colecionadora de cacarecos, torna-se um modelo do historiador materialista, a criança que, em seu protesto contra a escola e em sua autolibertação lúdica em relação ao mundo mobiliado do apartamento, vivido como mágico, experimenta a revolta do político, e, no meio de tudo isso, a criança que 'anda no carrossel', para a qual, em harmonia com a natureza, 'a vida é uma antiquíssima embriaguez da soberania'. Assim reúnem-se já na infância todos os temas da salvação futura." (WITTE, 2017, p. 73-74).

${ }^{4} \mathrm{O}$ conceito de mímesis é bastante antigo na história da filosofia, sendo pela primeira vez explorado na obra "Poética" de Aristóteles, quando reconhecia nessa habilidade a condição de sobrevivência do ser humano. Com o passar dos anos vários autores retomaram esse conceito na tentativa de compreenderem, de modo mais abrangente, as complexidades do existir. Entre esses pensadores encontramos Simmel, Elias, Huizinga, Benjamin, que relacionaram a faculdade mimética com 0 Mestre em Filosofia (UECE), Graduando em Pedagogia (UFC), Professor efetivo do Município de Fortaleza.
} Brasileiro, residente em Fortaleza - CE, E-mail: paulovictordealbuquerquesilva@gmail.com 
como seres dotados de afetividade, nos comunicamos com o mundo por meio da habilidade de imitar, ação majoritariamente dependente da produção de semelhanças. Para Benjamin a própria matéria traz em seu âmago a história cósmica que pode ser reproduzida na mimese, onde na filogenia, imitação de pessoas, a criança brinca de ser médico ou professor, enquanto a ontogenia, imitação de objetos, representaria a memória viva das coisas fenomênicas guardadas na memória pulsante do corpo infantil que imita um trem ou um avião ${ }^{5}$.

Ao nos depararmos com a criança no momento em que brinca encontraremos em seu ato corporal a representação viva da memória cósmica e mundana debulhada na materialidade. A intimidade da criança com a matéria é tal que em vários momentos ela se confunde com a mesma. Daí Benjamin argumentar que, quando de sua infância "conhecia todos os esconderijos do piso e voltava a eles como a uma casa na qual se tem a certeza de encontrar tudo sempre do mesmo jeito. (...) Aqui, ficava encerrado num mundo material que ia se tornando fantasticamente nítido..." (BENJAMIN, 1987, 91). Esse controle sobre o ambiente existencial produzirá na criança a "inervação criadora" ${ }^{6}$, onde somente se vislumbra o processo criativo quando inicialmente nos apossamos do instrumento de criação, a matéria.

Ao mergulhar no mundo material a criança traz de suas entranhas novas significações, doa-lhe novos sentidos, destrói outros velhos ou vigentes. "Não são as coisas que saltam das páginas em direção à criança que as vai imaginando - a própria criança penetra nas coisas durante o contemplar, como nuvem que se

fenômeno da infância. No texto "Jogo, mimese e infância: o papel do jogar infantil nos processos de construção do self' da socióloga Tamara Grigorowitschs encontramos de maneira bem lúcida essa relação. "O jogo infantil coletivo é uma forma de interação social permeada por ações miméticas. Pode-se afirmar que certas ações sociais são miméticas quando se constituem de movimentos que possuem correspondência com outros movimentos, isto é, no caso dos jogos, quando se percebe que os movimentos corpóreos de um determinado jogo podem ser reconhecidos em atividades da vida cotidiana; quando podem ser tratadas como apresentações corporais que possuem aspecto de representação, o que significa reconhecer que o jogo possui caráter performático e teatral. As ações miméticas são tanto ações independentes, que podem ser compreendidas em si mesmas, como também possuem correspondências com outros mundos. Isto é, os jogos são mundos próprios, mas que não estão isolados do mundo social, e sim inseridos nele, pois o jogar deve ser compreendido como uma série de ações e interações sociais específicas, nas quais as ações de jogo estão relacionadas às ações de não jogo." (GRIGOROWITSCHS, 2010, p. 232).

${ }^{5}$ Para mais vide: "A doutrina das semelhanças". In: Magia e Técnica, Arte e Política - Obras escolhidas I. Tradução de Sérgio Paulo Rouanet. São Paulo: Editora Brasiliense, 1985.

${ }^{6}$ Para mais vide: "Programa de um teatro infantil proletário". In: BENJAMIN, Walter. Reflexões sobre a criança, o brinquedo e a educação. Tradução de Marcus Vinicius Mazzari. São Paulo: Duas Cidades; Ed. 34, 2002. p. 116.

Mestre em Filosofia (UECE), Graduando em Pedagogia (UFC), Professor efetivo do Município de Fortaleza. Brasileiro, residente em Fortaleza - CE, E-mail: paulovictordealbuquerquesilva@gmail.com 
impregna do esplendor colorido desse mundo pictórico." (BENJAMIN, 2002, 69). Assim como em um livro, não são as coisas que saltam sobre as crianças mas os próprios seres minúsculos que adentram na matéria. Nesta relação quanto maior a simplicidade material mais ampla será a abertura para a capacidade criativa da infância, que em seu ato fantasioso, antes de afastar, aproxima-se das coisas garantindo o controle contínuo sobre elas.

O contato direto com o mundo para a criança majoritariamente se dá através da brincadeira. É evidente que pensarmos em regras para a esfera lúdica da infância é o mesmo que blasfemar, mas o que seria o brincar senão uma profanação, no sentido religioso do mito, que a modernidade realiza, uma desconstrução dos valores enraizados no interior da moral humana. Isso significa que a criança é um ser extemporâneo, uma criatura até certo ponto deslocada da história viva, em que tudo o que ela toca ganha um teor de extemporaneidade, se manifestando ambiguamente como um confronto ao estabelecido bem como reconstruindo algo novo. Nesse sentido, o brinquedo não é um "Outro", mas uma extensão fisiológica do seu corpo, e na mesma medida em que damos maior ou menor atenção a certos órgãos que nos compõem, as crianças se debruçam sobre as coisas do mundo ou da natureza carregando-as para sua "realidade feérica".

Quando nos deparamos com o pensamento filosófico conhecemos as realidades conceituadas como "natureza", como aquilo que não sofreu a alteração humana, de "mundo", como sendo tudo aquilo proveniente do espírito. Agora, por meio do fenômeno da infância vemos surgir o "feérico", uma realidade autentica com suas "regras", seu "tempo", sua "espacialidade". Ao explanar a relação da criança com os produtos residuais dirá Benjamin: "Neles, estão menos empenhados em reproduzir as obras dos adultos do que em estabelecer entre os mais diferentes materiais, através daquilo que criam em suas brincadeiras, uma relação nova e incoerente." (BENJAMIN, 2002, 104). A frequente incoerência presente no ato lúdico Ihe distancia de uma pretensão política, mas em contrapartida abre em sua inconsciência a possibilidade para o verdadeiro estado de exceção que irrompe no agora decisivo, pois a falta de um caminho pré-estabelecido ou de um ideal, lhe garantem a constante experiência do excesso, do desvio, que se voltam contra o dado.

$\mathrm{Na}$ teoria filosófica benjaminiana as imagens podem ressurgir em momentos Mestre em Filosofia (UECE), Graduando em Pedagogia (UFC), Professor efetivo do Município de Fortaleza.

Brasileiro, residente em Fortaleza - CE, E-mail: paulovictordealbuquerquesilva@gmail.com 
oportunos, instantes decisivos de interferência no agora existencial. Ao longo de seus escritos podemos perceber de que maneira as imagens de pensamento elaboradas por Benjamin, que o acompanham em grande parte de sua história, emergem de maneira latente e potente como lampejos inconscientes nos últimos escritos de sua vida. Faz parte do projeto metodológico benjaminiano educar o olhar para as imagens que resplandecem em meio aos acontecimentos históricos, decidimos direcionar esse olhar ao mundo minúsculo e feérico da infância. Vale ressaltar o quanto a teoria benjaminiana está mergulhada em meio a concepções teóricas da filosofia estética, servindo-se de conceitos como o de imagem, imaginação, cores, fotografia, etc. que servem de arcabouço teórico para se pensar a política contemporânea. Logo, pretendemos com essas imagens da infância causar uma ruptura nos eventos contínuos da história, sustentadas pelo ideal de "progresso" ou "época de decadência", duas faces da mesma moeda.

\begin{abstract}
Não é que o passado lança sua luz sobre o presente ou que o presente lança sua luz sobre o passado; mas a imagem é aquilo em que o ocorrido encontra o agora num lampejo, formando uma constelação. Em outras palavras: a imagem é a dialética na imobilidade. (BENJAMIN, 2009, p. 504).
\end{abstract}

Ou seja, a infância através do seu ato de brincar produz em cada ação, na captura de cada flash, imagens que saltam no agora da cognoscibilidade como iluminações profanas de seres diabólicos e incoerentes. Sem planejamentos ou normatizações, tudo emana dela como em um passe de mágicas; a exceção é seu segundo nome.

\title{
1 A iluminação profana da infância rompendo com o continuum histórico.
}

É justamente a concepção dialética contida na filosofia benjaminiana que the faz perceber como a inocência infantil, que se vislumbra com tamanha facilidade face às argúcias da mercadoria, enquanto criaturas mimeticamente caricaturais de seu tempo, também trazem em seu âmago o "caráter destrutivo"7 que, em nossa concepção, é desfigurador da espacialidade fantasmagórica. Daí a pretensão,

\footnotetext{
${ }^{7}$ Para mais vide: "O caráter destrutivo". In: Imagens de pensamento/Sobre o haxixe e outras drogas. Tradução de João Barrento. Belo Horizonte: Autêntica editora, 2013.

Mestre em Filosofia (UECE), Graduando em Pedagogia (UFC), Professor efetivo do Município de Fortaleza. Brasileiro, residente em Fortaleza - CE, E-mail: paulovictordealbuquerquesilva@gmail.com
} 
desde a mais tenra idade, nas tentativas educacionais em manter as crianças numa eterna distração, manifestando o substancial intuito da sociedade mercadológica. 0 problema é que cada geração que vem ao mundo convoca seus habitantes gradativamente ao "despertar". 8 A criança é o novo que vem ao mundo e a todo custo deve ser engolida pela fantasmagoria social e espacial. O confronto descrito por Benjamin de gerações entre os pequeninos e o adulto manifestado no texto "Brinquedos e jogos"9, é a expressão do choque contra o status quo planejado pelas argúcias mercadológicas da metrópole ${ }^{10}$.

No caderno K das "Passagens" o filósofo alemão revela o quanto a nova geração, que mesmo com todo seu vigor adormece no berço espectral, espera o momento exato para o despertar. "O fato de termos sido crianças nesta época faz parte de sua imagem objetiva. Ela tinha que ser assim para fazer nascer esta geração. Quer dizer: no contexto onírico procuramos um momento teleológico. Este momento é a espera." (BENJAMIN, 2009, 435). Em sequência conclui: "O sonho espera secretamente pelo despertar (...)". Como podemos perceber, na imagem objetiva de nossa infância encontra-se, de forma inerente, o impulso de despertar do mundo onírico fantasmagórico que nos encontramos. Assim como fisiologicamente nosso corpo sabe exatamente o momento de acordar, esperamos com a mesma certeza que as imagens messiânicas nos despertem do sonho moderno, sendo a infância uma dessas imagens. ${ }^{11}$ Se ainda não nos encontramos conscientemente despertos, nosso inconsciente nos sussurra o acordar, que enquanto ato corpóreo

\footnotetext{
${ }^{8}$ Essa teoria em certo sentido também é compartilhada pela filósofa Hannah Arendt através do seu conceito de natalidade, como podemos perceber no último parágrafo de sua obra "Origens do totalitarismo": "Mas permanece também a verdade de que todo fim na história constitui necessariamente um novo começo; esse começo é a promessa, a única "mensagem" que o fim pode produzir. O começo, antes de tornar-se evento histórico, é a suprema capacidade do homem; politicamente, equivale à liberdade do homem. Initium ut esset homo creatus est - 'o homem foi criado para que houvesse um começo', disse Agostinho. Cada novo nascimento garante esse começo; ele é, na verdade, cada um de nós." (ARENDT, 2006, p. 421).

${ }^{9}$ Vide: Reflexões sobre a criança, o brinquedo, a educação. Tradução de Marcus Vinicius Mazzari. São Paulo: Duas Cidades, Editora 34, 2009.

${ }^{10}$ A relação entre a fantasmagoria da metrópole e a infância foi exposta, por nós, anteriormente no $14^{\circ}$ volume dos Cadernos Walter Benjamin. Para mais vide: SILVA. P. V. A. "O fenômeno da infância face aos espaços fantasmagóricos da metrópole" in: Cadernos Walter Benjamin N. 14 - JaneiroJunho de 2015, acessível no site: www.gewebe.com.br

11 A relação entre o espaço fantasmagórico onírico da metrópole e o despertar é muito bem explorada por Witte quando o mesmo afirma: "Desse modo, entender a história da humanidade como o seu sonho não significa outra coisa senão o fato de que na história as verdadeiras pulsões e desejos do homem, que anseia por plenitude e felicidade, chegam de fato a se expressar, mas apenas em sua forma deslocada, recalcada. Esse trabalho de sonho impede o homem de despertar, o que significaria um fim da história e um alvorecer do reino messiânico." (WITTE, 2017, p. 125).

Mestre em Filosofia (UECE), Graduando em Pedagogia (UFC), Professor efetivo do Município de Fortaleza.
} Brasileiro, residente em Fortaleza - CE, E-mail: paulovictordealbuquerquesilva@gmail.com 
encontra-se na matéria - que possui seu lado teológico - profanando a metafísica transcendente como o faz a criança. Isso se deve ao fato da própria infância ser capaz de fazer reluzir novas imagens que nos permitem confrontar a realidade onírica. No mesmo caderno dirá Benjamin: "Tarefa da infância: integrar o novo mundo ao espaço simbólico. A criança é capaz de fazer algo que o adulto não consegue: rememorar o novo." (BENJAMIN, 2009, 435). Ou seja, cada infância reconhece no mundo o novo que nos surge, já que sua sensibilidade the permite uma apuração por demais detalhada dos fatos, enquanto o adulto, rodeado pelas frenéticas novidades do mercado, esquece da centelha que provoca a mudança, o despertar. A criança nos rememora tais imagens, pois o seu olhar neófito não enxerga o objeto enquanto mais uma novidade, antes ela espanta-se com o novo. Como afirma Benjamin que, "a cada formação verdadeiramente nova da natureza e no fundo também a técnica é uma delas - correspondem novas 'imagens'. Cada infância descobre essas novas imagens para incorporá-las ao patrimônio de imagens da humanidade." (BENJAMIN, 2009, 435). Essa passagem serve para nos alertar como Walter Benjamin, enquanto um ser adulto, depende do olhar infantil para rememorar a verdadeira formação da nova natureza e da técnica. Desviandose das novidades construídas pelo teor fantasmagórico o filósofo depara-se com a imagem do novo, que agora em sua nova abertura nos permite revolucionar. A criança está sempre nos convidando a reutilizar as imagens dialéticas produzidas pela humanidade.

O despertar da imagem dialética, quando surge, não se encontra inserido na ideologia do progresso, ele nos vem de forma descontínua. O passado se revela através de um caráter atualizado superior, o que lhe permite ressurgir em momentos preciosos, fora de uma escala linear de tempo, disso decorre seus desvios contrários ao progresso. O fenômeno infantil nos ajuda a rememorar tais imagens que, em sua descontinuidade, retornam não de maneira simplesmente histórica, mas através das tomadas de decisão política no "tempo do agora" (Jetztzeit). Nesse sentido faz-se necessário o reconhecimento do limiar na imagem que desperta, pois somente poderemos utilizá-la em sua solidez com suas arestas, como o fragmento de um mosaico. A metrópole fantasmagórica obedece a linearidade ideológica do progresso fazendo sucumbir os "rituais de passagem", impondo em seu lugar a transitoriedade ininterrupta entre os ambientes oníricos, morada do sonho. Tal Mestre em Filosofia (UECE), Graduando em Pedagogia (UFC), Professor efetivo do Município de Fortaleza. Brasileiro, residente em Fortaleza - CE, E-mail: paulovictordealbuquerquesilva@gmail.com 
fenômeno que esboça a pobreza das experiências do "limiar" (Schwelle) é muito bem descrito por Benjamin no fragmento "Ritos de passagem" do caderno O:

\begin{abstract}
Ritos de passagem - assim se denomina no folclore as cerimônias ligadas à morte, ao nascimento, ao casamento, à puberdade etc. $\mathrm{Na}$ vida moderna, estas transições tornaram-se cada vez mais irreconhecíveis e difíceis de vivenciar. Tornamo-nos muito pobres em experiências limiares. $\mathrm{O}$ adormecer talvez seja a única delas que nos restou. ( $E$, com isso, também o despertar). $E$, finalmente, tal qual as variações das figuras dos sonhos, oscilam também em torno de limiares os altos e baixos da conversação e as mudanças sexuais do amor. (...) O limiar [Schwelle] deve ser rigorosamente diferenciado da fronteira [Grenze]. O limiar é uma zona. Mudança, transição, fluxo estão contidos na palavra schwellen (inchar, entumescer), e a etimologia não deve negligenciar estes significados. Por outro lado, é necessário determinar o contexto tectônico e cerimonial imediato que deu à palavra o seu significado. (BENJAMIN, 2009, p. 535).
\end{abstract}

A distinção entre as experiências do limiar são ludibriadas pelo aparato fantasmagórico, assim como não reconhecemos quando os sonhos se transmutam. Esse jovial posicionamento antropológico do homem na metrópole Ihe dificulta a distinção entre os objetos fruto da novidade ou do verdadeiramente novo, acomoda o seu espírito na locomotiva ininterrupta e não na parada reflexiva, no puxar do "freio de mão" de emergência. ${ }^{12} \mathrm{O}$ estanque faz-se necessário para a produção intelectual revolucionária. Podemos vislumbrar no pensamento benjaminiano a importância dada a ruptura com o tempo homogêneo quando o autor cria sua teoria do conhecimento contida nos cadernos $\mathrm{N}$ das "Passagens". Logo no início do capítulo encontramos sua pretensão com a obra, quando ele afirma: "É o caso deste projeto, que deve caracterizar e preservar os intervalos da reflexão, os espaços entre as partes mais essenciais deste trabalho, voltadas com máxima intensidade para fora." (BENJAMIN, 2009, 499). Fica-nos evidente que os intervalos de reflexão somente serão possíveis fora do tempo fantasmagórico da metrópole moderna. Continua dizendo: "Construo meus cálculos sobre os diferenciais de tempo."

\footnotetext{
${ }^{12} \mathrm{Na}$ obra "Limiar, aura e rememoração: Ensaios sobre Walter Benjamin", Jeanne Marie Gagnebin nos relata o quanto a infância contém em si esse caráter de espera, desvio da locomotiva do capital. "Prenhe de um futuro desconhecido, a infância também é atravessada por uma temporalidade da espera e da paciência, que tem no limiar seu espaço privilegiado. A infância ainda sabe fruir de um tempo sem determinação, de um tempo que não possui um fim prefixado, um tempo de espera de um desconhecido que não pode ser antecipado por uma decisão precipitada, mesmo quando os adultos tentam encaixar a criança numa estratégia de previsibilidade da vida. Assim, o presente é pleno da intensidade da descoberta e, simultaneamente, pleno de angústia e de esperança com relação ao futuro, como se o tempo da espera (Warten) redobrasse, por sua necessária paciência, o fervor do vivido, que não voltará mais com essa abertura." (GAGNEBIN, 2014, p. 42).

Mestre em Filosofia (UECE), Graduando em Pedagogia (UFC), Professor efetivo do Município de Fortaleza.
} Brasileiro, residente em Fortaleza - CE, E-mail: paulovictordealbuquerquesilva@gmail.com 
(BENJAMIN, 2009, 499). Os caminhos trilhados por Benjamin encontram-se fora das rotas tradicionais, seus desvios abrem novas possibilidades que guiam 0 pensamento ao desconhecido, seu lado infantil não lhe permite aceitar o real sem questioná-lo.

Dando prosseguimento a sua pesquisa Walter Benjamin expõe o lado pedagógico do seu projeto que corrobora diretamente com o que pretendemos defender em nosso artigo. Diz o filósofo: "Educar em nós o médium criador de imagens para um olhar estereoscópico e dimensional para a profundidade das sombras históricas." (BENJAMIN, 2009, 500). Esse medium criador de imagens encontra-se justamente no olhar infantil que é o único capaz de rememorar o verdadeiramente novo em meio ao mundo onírico capitalista. $\mathrm{O}$ ato de despertar do sonho social somente será realizado quando insistirmos, cotidianamente, em perceber o fenômeno da metrópole, entre outras coisas, com o olhar da criança que vislumbra as imagens construídas pela humanidade. Até este ponto da pesquisa podemos perceber uma dupla faceta proveniente do universo infantil: por um lado a própria postura dos pequeninos perante o mundo onírico que os circunda; por outro o quanto sua existência produz em nós a aparição de imagens dialéticas desviantes. O que nos é certo é que tanto um aspecto quanto o outro engendram rupturas com o continuum histórico.

Ao pensar uma metodologia para a "dialética da história cultural" Benjamin afirma o quanto se faz necessário um empreendimento que se debruce sobre todos os fragmentos da realidade, sem distinções de relevância qualitativas, "até que todo o passado seja recolhido no presente em uma apocatástase histórica" (BENJAMIN, 2009, 501). Tal atitude se deve ao fato do autor estar a procura do que ele chama de "contrastes dialéticos", que seriam muito mais importantes ao seu trabalho. Interessante notar como a criança, enquanto brinca, também não faz distinção entre quais objetos seriam mais significativos ou não, e como devido ao seu olhar rememorador, faz reluzir imagens relevantes ao projeto benjaminiano. Constitui parte do seu propósito metodológico aniquilar o ideal de progresso histórico que realiza uma seleção cultural daquilo que seria mais considerável para sua marcha, em seu lugar ele propõe o conceito de "atualização". Daí afirmar que, "a superação dos conceitos de 'progresso' e de 'época de decadência' são apenas dois lados de uma mesma coisa." (BENJAMIN, 2009, 503). Já que a marcha do "progresso" deixa Mestre em Filosofia (UECE), Graduando em Pedagogia (UFC), Professor efetivo do Município de Fortaleza. 
ao seu redor os escombros dos vencidos provenientes dessa trajetória.

Ainda pensando na estrutura dialética contida no fenômeno infantil, encontramos em seu olhar a capacidade em interligar o mundo da tecnologia moderna com o mundo arcaico dos símbolos da mitologia. No primeiro momento, quando a criança se depara com as novidades tecnológicas deixa se levar pelo esplendor do objeto que lhe encanta, mas se nos aproximarmos percebemos 0 modo real com que ela se relaciona com o mesmo. Vejamos o que dirá Benjamin: "Cada infância realiza algo grande e insubstituível para a humanidade. (...) sua curiosidade por toda sorte de invenções e máquinas, liga as conquistas tecnológicas aos mundos simbólicos antigos." (BENJAMIN, 2009, 503). A curiosidade encarada de frente pelo homem primitivo, quando deparava-se com o mistério simbólico mítico é, a cada geração, revivida pela infância. Isso demonstra o mesmo caráter místico nas fantasmagorias de nosso tempo. É evidente que a relação com o mistério não se dá mais como entre os antigos, neles o peso da tradição mantinha encoberto os momentos históricos primevos dentro de um "universo de memória" (Merkwelten). A perda com o elo do passado foi muito bem descrita por Benjamin no texto "O narrador" (Der Erzähler), quando a memória era preenchida pelas experiências vivas da coletividade e transmitidas através da narração oral. "O conselho tecido na substância viva da existência tem um nome: sabedoria. A arte de narrar está definhando porque a sabedoria - o lado épico da verdade - está em extinção." (BENJAMIN, 1985, 200-201). ${ }^{13}$ Agora, no plano da "visibilidade" (Anschaulichkeit), tudo se desvela em sua superficialidade, onde a velocidade da produção técnica determina o ritmo de um novo "universo de memória", lugar desperto pela infância.

Ao pensarmos a rememoração não dizemos que o passado vai de encontro ao presente ou vice-versa, afirmamos que, enquanto "imagem", o ocorrido encontra o agora através de um lampejo que salta no instante preciso. Como afirma Benjamin: "Pois, enquanto a relação do presente com o passado é puramente temporal e contínua, a relação do ocorrido com o agora é dialética - não é uma progressão, e sim uma imagem, que salta." (BENJAMIN, 2009, 504). Pois o "agora"

\footnotetext{
${ }^{13}$ No original: "Le conseil tissé dans l'étoffe d'une vie vécue devient sagesse. L'art de narrer est en déclin parce que l'aspect épique de la vérité, la sagesse, tend à disparaître." (BENJAMIN, 2011, p. 269).
} 
preciso, clama pela "imagem autêntica" que não é arcaica, ela está livre do tempo cronológico encontrando-nos como "imagem dialética na imobilidade", neste sentido, se dispõe fora da marcha do progresso histórico. Tais imagens lampejam nos momentos de perigo, críticos e de risco, são reveladas no "agora da cognoscibilidade" (BENJAMIN, 2009, 505), empossados pela consciência desperta. A metodologia materialista da história defendida por Benjamin leva o passado a colocar o presente em um constante alerta de situação crítica, devido seu caráter dialético que percorre o agora. Na mesma proporção, a cada geração, qualquer criança confronta o seu presente levando-o a momentos de crise.

Como podemos perceber o fenômeno infantil, através de sua ludicidade, linguagem, caráter destrutivo, percepção rememorativa, faz saltar imagens dialéticas nos momentos de perigo no agora cognoscível, empreendendo rachaduras, fissuras e desvios no continuum histórico. "A imagem dialética é uma imagem que lampeja. É assim, como uma imagem que lampeja no agora da cognoscibilidade, que deve ser captado o ocorrido." (BENJAMIN, 2009, 515). Cabe a nós capturarmos tais momentos preciosos visando uma intervenção contra o progresso. Para tanto o materialista histórico deve, no momento destrutivo, provocar uma explosão na marcha de catástrofes que se acumulam no percurso histórico, rompendo com o status quo. A própria imagem, por ser dialética, encontra-se fora do continuum, a espreita do agora, e portanto imobiliza o pensamento. ${ }^{14}$ Diz Benjamin: "Ao pensamento pertencem tanto o movimento quanto a imobilização dos pensamentos. Onde ele se imobiliza numa constelação saturada de tensões, aparece a imagem dialética. Ela é a cesura no movimento do pensamento." (BENJAMIN, 2009, 518). Este processo dialético saturado de tensões é a mônada.

Eu seu último texto escrito em 1940 "Sobre o conceito da história" (Über den Begriff der Geschichte), Benjamin dita que percurso deve seguir o materialista histórico em sua investigação. "Cabe ao materialismo histórico fixar uma imagem do

\footnotetext{
${ }^{14}$ Para contribuir com nosso argumento acerca da intervenção política no agora, através da imagem dialética que surge como relampejo no inconsciente coletivo, tomamos as palavras de Jeanne Marie Gagnebin: "A filosofia da história de Benjamin insiste nestes dois componentes da memória: na dinâmica infinita de Erinnerung, que submerge a memória individual e restrita, mas também na concentração do Eingedenken, que interrompe o rio, que recolhe, num só instante privilegiado, as migalhas dispersas do passado para oferecê-las à atenção do presente. As imagens dialéticas nascem da produção da lembrança, mas só adquirem uma forma verdadeira através da intensidade imobilizadora da rememoração." (GAGNEBIN, 2013, p. 80).
}

Mestre em Filosofia (UECE), Graduando em Pedagogia (UFC), Professor efetivo do Município de Fortaleza. Brasileiro, residente em Fortaleza - CE, E-mail: paulovictordealbuquerquesilva@gmail.com 
passado, como ela se apresenta, no momento do perigo, ao sujeito histórico, sem que ele tenha consciência disso." (BENJAMIN, 1985, 224). ${ }^{15}$ Precisamos confrontar o conformismo em detrimento da tradição assim como faz a criança em sua imagem quando brinca. Ela nos revela o quanto tal ato é real, já que a mesma rompe efetivamente com tais normas, um desvio não utópico. Para tanto os pequeninos não criam um laço de dependência com a tradição dos opressores, uma empatia por algo específico e único, elas se envolvem com tudo aquilo que Ihes causa prazer ou utilidade no jogar. A empatia vivida pelo povo europeu junto ao ideal de progresso fez com que aceitassem, de maneira incontestável, todos os símbolos históricos que prometiam a garantia do futuro promissor, mesmo que para isso o "estado de exceção" fosse necessário a esta evolução. Neste sentido, para Benjamin, faz-se forçoso ao materialista histórico conduzir um novo "estado de exceção" mais verdadeiro com decisões que incidam sobre o agora preciso, causando rupturas com o continuum, o que para nós a imagem da infância seria uma das mais eficientes, sendo portanto, tão utilizada pelo filósofo ao longo de seus escritos. A imagem em relampejo da infância no momento de perigo, antes de mais nada, nos serve como possibilidade de intervenção política no agora messiânico contra o continuum histórico capitalista fascista.

\section{REFERÊNCIAS}

ARENDT, H. Origens do Totalitarismo. Tradução de Roberto Raposo. São Paulo: Companhia das Letras, 2006.

BENJAMIN, Walter. A hora das crianças: narrativas radiofônicas. Tradução de Aldo Medeiros. Rio de Janeiro: NAU Editora, 2015.

. Écrits français. Paris: Éd. Gallimard, 2011.

. Imagens de pensamento/Sobre o haxixe e outras drogas.

Tradução de João Barrento. Belo Horizonte: Autêntica editora, 2013.

Magia e Técnica, Arte e Política - Obras escolhidas I.

Tradução de Sérgio Paulo Rouanet. São Paulo: Editora Brasiliense, 1985.

\footnotetext{
15 No original: "Le matérialisme historique est tout attaché à capter une image du passé comme elle se présente au sujet à l'improviste et à l'instant même d'un danger suprême." (BENJAMIN, 2011, p. 436).

Mestre em Filosofia (UECE), Graduando em Pedagogia (UFC), Professor efetivo do Município de Fortaleza. Brasileiro, residente em Fortaleza - CE, E-mail: paulovictordealbuquerquesilva@gmail.com
} 
. Passagens. Tradução do alemão Irene Aron; tradução do francês Cleonice Paes Barreto Mourão. Belo Horizonte: Editora UFMG. 2009.

Reflexões sobre a criança, o brinquedo, a educação. Tradução de Marcus Vinicius Mazzari. São Paulo: Duas Cidades, Editora 34, 2009.

Rua de mão única: Infância berlinense: 1900. Tradução de João Barrento. Belo Horizonte: Autêntica Editora, 2013.

Rua de mão única - Obras escolhidas II. Tradução de Rubens Rodrigues Torres Filho e José Carlos Martins Barbosa. São Paulo: Editora Brasiliense, 1987.

CALLADO, Tereza de Castro. Walter Benjamin - A Experiência da Origem, Fortaleza: Eduece, 2006.

CALLADO. Tereza de Castro. Cadernos Walter Benjamin (Org.), acessível no site: www.gewebe.com.br

GAGNEBIN, Jeanne Marie. História e narração em Walter Benjamin. São Paulo: Perspectiva, 2013.

\section{Limiar, aura e rememoração: ensaios sobre Walter}

Benjamin. São Paulo: Editora 34, 2014.

GRIGOROWITSCHS, Tamara. Jogo, mimese e infância: o papel do jogar infantil nos processos de construção do self. In__: Revista Brasileira de Educação. v. 15, n. 44, mai./ago. 2010. Acessível em:

http://www.scielo.br/pdf/rbedu/v15n44/v15n44a03.pdf

HUIZINGA, Johan. Homo ludens: o jogo como elemento da cultura. Tradução de João Paulo Monteiro. São Paulo: Perspectiva, 2014.

KANT, Immanuel. Sobre a Pedagogia. Tradução de Francisco Cock Fontanella. Piraricaba: Editora Unimep, 1999.

SILVA. P. V. A. "O fenômeno da infância face aos espaços fantasmagóricos da metrópole" in_: Cadernos Walter Benjamin N. 14 - Janeiro-Junho de 2015, acessível no site: www.gewebe.com.br

WITTE, Bernd. Walter Benjamin: uma biografia. Tradução de Romero Freitas. Belo Horizonte: Autêntica Editora, 2017. 